\title{
PID-Based Design of DC Motor Speed Control
}

\author{
Irfan Irhamni ${ }^{1}$, Riries Rulaningtyas ${ }^{1}$, Riky Tri Yunardi $^{1}$ \\ ${ }^{1}$ Department of Physics, Faculty of Science and Technology, Universitas Airlangga, Surabaya 60115, Indonesia \\ a) Corresponding author: riries-r@fst.unair.ac.id \\ Article History \\ Received : 23 March 2021, Revised : 13 April 2021, Accepted : 16 April 2021, Online : June 2021
}

\begin{abstract}
DC motor is an easy-to-apply motor but has inconsistent speed due to the existing load. PID (Proportional Integral Differential) is one of the standard controllers of DC motors. This study aimed to know the PID controller's performance in controlling the speed of a DC motor. The results showed that the PID controller could improve the error and transient response of the system response generated from DC motor speed control. Based on the obtained system response data from testing and tuning the PID parameters in controlling the speed of a DC motor, the PID controller parameters can affect the rate of a DC motor on the setpoint of 500, 1000, 1500: $\mathrm{Kp}=0.05, \mathrm{Ki}=0.0198, \mathrm{Kd}=0.05$.
\end{abstract}

\section{INTRODUCTION}

DC motor is a standard actuator since automobiles and robotics mainly depend on the DC voltage system. Moreover, a rectifier circuit can provide the desired DC power source without using the DC primary voltage source. DC motor also allows motor speed variations [1].

Speed control determines the rate of the electric engine rotation on DC motor applications. However, the signal error on the output command often occurs because of the incompatible rotation to the setpoint. Therefore, a closedloop control system was needed to control and give feedback on the incompatible output [2].

\section{MATERIALS AND METHOD}

This study used a computer, tachometer, Arduino, DC motor, Drive Halff Bridge motorbike, and Rotary Encoder. Data were collected to test the DC motor's performance and work by observing its stability and suitability to the setpoint, which obtained from various specifications of the transient response, including:

- Rise time (Tr): the time takes for the output to move from $0 \%$ to $100 \%$ of the setpoint condition.

- Delay time (Td): the time takes for the output to reach $50 \%$ of the setpoint condition.

- Peak time (Tp): the time takes for the output to reach its maximum value.

- Maximum Overshoot (Mp): the height that exceeds the setpoint value.

- Setting time (Ts): the time takes the output to reach a setpoint condition with a given tolerance.

- Error Steady Set (ess): obtained from the setpoint.

- Maximum Overshoot (Mp): the peak value from the graphical response.

\section{RESULTS AND DISCUSSIONS}

This study used the trial-and-error method to determine the value of the PID (Proportional Integral Differential) parameter. The first step was to obtain the nominal error value by entering $\mathrm{Kp}, \mathrm{Ki}$, and $\mathrm{Kd}$. 
TABLE 1. PID Test Value

\begin{tabular}{ccc}
\hline Trial & $\mathrm{Kp}$ & $\mathrm{Ki}$ \\
\hline 1 & 0.05 & 0.0198 \\
2 & 0.09 & 0.01 \\
3 & 0.02 & 0.01 \\
\hline
\end{tabular}

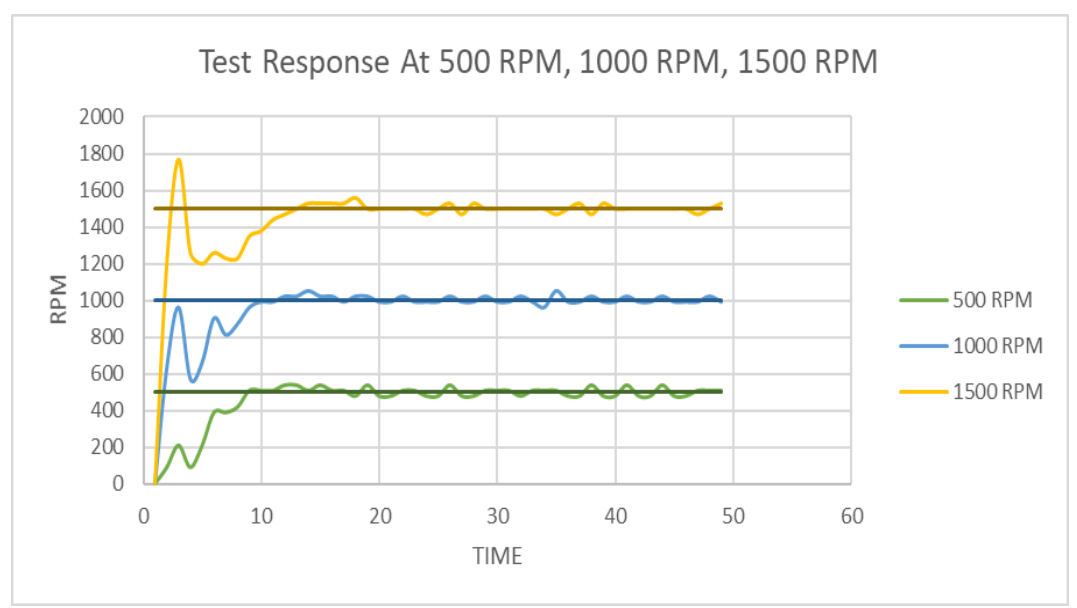

FIGURE 1. First Trial Response Data

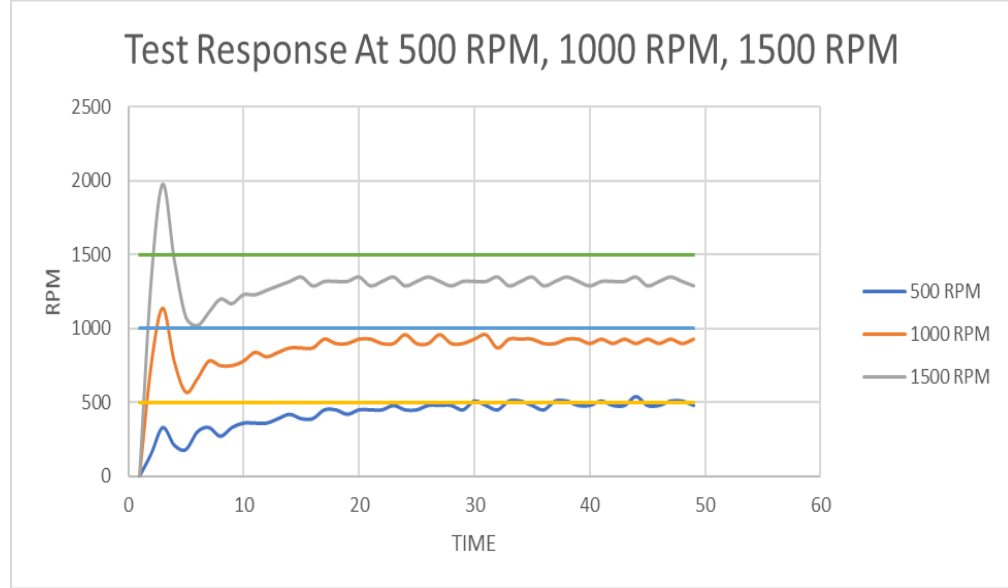

FIGURE 2. Second Trial Response Data

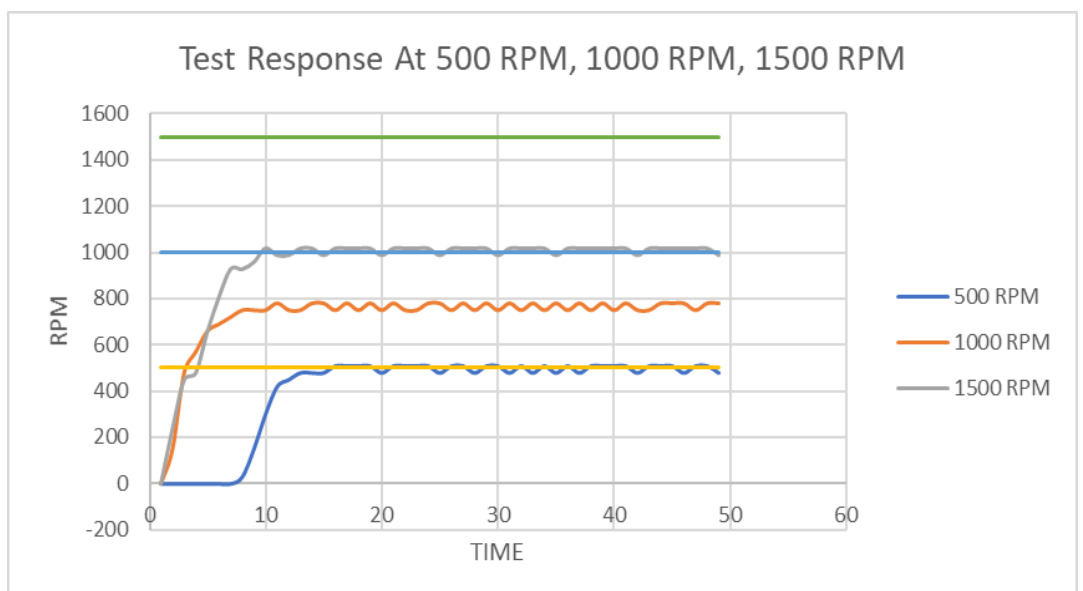

FIGURE 3. Third Trial Response Data 
The test was carried out by changing the RPM value of 500, 1000, 1500 for each trial and showed in graphical data, as shown in Figure 1, Figure 2, and Figure 3. Table 2 showed the final data response.

TABLE 2. Head CT-Scan Data Based on Theoretical Formula

\begin{tabular}{cccccccc}
\hline Trial & $\begin{array}{c}\text { Set } \\
\text { point }\end{array}$ & Kp & Ki & Kd & Ts & ess & Mp \\
\hline \multirow{2}{*}{1} & 500 & 0.05 & 0.0198 & 0.05 & 0.5 & 0.02 & 0.022 \\
& 1000 & 0.05 & 0.0198 & 0.05 & 0.5 & 0.01 & 0.01 \\
& 1500 & 0.05 & 0.0198 & 0.05 & 0.5 & 0.006 & 0.166 \\
\hline \multirow{2}{*}{2} & 500 & 0.009 & 0.01 & 0.02 & 5 & 0.02 & 0.01 \\
& 1000 & 0.009 & 0.01 & 0.02 & 5 & -0.01 & 0.6 \\
& 1500 & 0.009 & 0.01 & 0.02 & 5 & -0.13 & 0.332 \\
\hline \multirow{2}{*}{3} & 500 & 0.02 & 0.01 & 0.02 & 7 & 0.004 & 0.004 \\
& 1000 & 0.02 & 0.01 & 0.02 & 7 & -0.208 & -0.208 \\
& 1500 & 0.02 & 0.01 & 0.02 & 7 & -0.333 & -0.333 \\
\hline
\end{tabular}

The best response from the first trial showed RPM 1000 and ess 0.01 , in which the final value was near the setpoint. The lower rotation to the setpoint caused harmful ess data. However, the RPM 500 gave the best ess data of the second and third trials, 0.02 and 0.004 , respectively.

The motor rotation was held back by the object that touched the motor disc as the disturbance was given. Figure 4 showed the graphical response of the disturbance test.

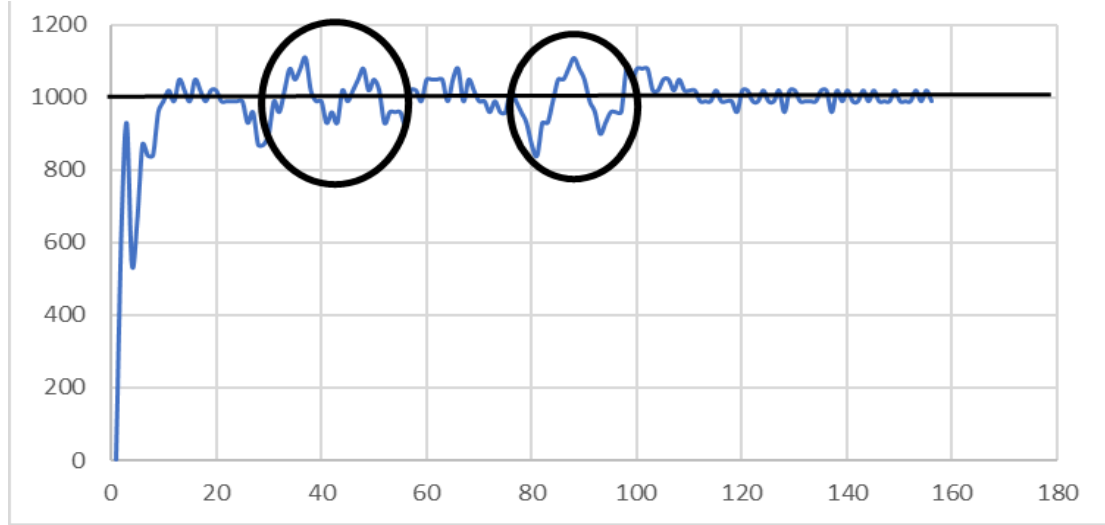

FIGURE 4. The Response of Disturbance Test at 1000 RPM

Figure 4 implied that the disturbance test on the motor rotation when the response was running caused the decreased response twice. The steady-state error (ess) value was $0.1 \%$, and the Maximum Overshoot (Mp) value was $0.02 \%$, but the response followed the steady-state.

\section{CONCLUSION}

Based on the system response data obtained from testing and tuning the PID parameters in controlling the speed of a DC motor, the PID controller parameters can affect the speed of a DC motor Setpoint 500, 1000, 1500: Kp = 0.05, $\mathrm{Ki}=0.0198, \mathrm{Kd}=0.05$.

\section{REFERENCE}

1. Reza, M. S., Al Mamun, M. A., Rahman, M. A., \& Begum, M. (2015). Design and Development of LabVIEW Based DC Motor Speed and Direction Control System. International Journal of Engineering Research \& Technology, 4(05), 2278-0181.

2. Toha, Kusuma. (2008). PID Control Design For DC Motors Using H8 / 3052 Microcontroller. Depok. 